\title{
Evaluaciòn de subproductos agrícolas sometidos a fermentación en estado solido.
}

\author{
Evaluation of agricultural subproducts submitted to fermentation in a \\ solid state.
}

\section{Gabriel Fernando Saavedra Montañez ${ }^{1}$ „;Deisy Carolina Cala Guerrero² ;Carlos Eduardo Rodríguez Molano ${ }^{3}$}

${ }^{1}$ Investigador, Grupo de Investigación en Bioquímica y Nutrición Animal, Dirección de Investigaciones, Facultad de Ciencias Agropecuarias, Universidad Pedagógica y Tecnológica de Colombia (UPTC). Tunja.

${ }^{2}$ Investigador, Grupo de Investigación en Bioquímica y Nutrición Animal, Universidad Pedagógica y Tecnológica de Colombia (UPTC). Tunja.

${ }^{3}$ Investigador, Grupo de Investigación en Bioquímica y Nutrición Animal, Dirección de Investigaciones, Facultad de Ciencias Agropecuarias, Universidad Pedagógica y Tecnológica de Colombia (UPTC). Tunja. Autor de Correspondencia: ceromol@gmail.com

\section{Resumen}

Estudio para determinar calidad composicional de un alimento preparado mediante fermentación en estado sólido con residuos agrícolas y agroindustriales como papazanahoria - manzana y durazno, estimulada por un preparado microbiano a base de bacterias acido lácticas. Se evaluaron 8 tratamientos T1 (30\% papa); T2 (30\% zanahoria); T3 (30\% manzana); T4 (30\% durazno); T5 (50\% papa) T6 (50\% zanahoria); T7 (50\% manzana); T8 (50\% durazno); mezclados con aditamentos como: $0.15 \%$ de carbonato de calcio, de urea, minerales, melaza, y sulfato de magnesio. Mediante técnicas de laboratorio se evaluó pH, FC, PC, cenizas, MS y humedad, a las 0,24 y 48 horas del proceso. Los resultados obtenidos evidencian una disminución del pH estabilizándose entre 4.4 y 5.1; la proteína cruda aumenta en cada punto de muestreo, los tratamientos con diferentes porcentajes de inclusión de papa reportan valores más altos; la humedad se mantuvo entre 35 a $74 \%$, óptimo para el proceso fermentativo, las cenizas entre $5 \%$ y $7.8 \%$; los valores de 
materia seca aumentan en cada punto de evaluación, los mejores resultados se observaron con el $50 \%$ de inclusión de papa y zanahoria con valores de $62.18 \%$ y $63.67 \%$ respectivamente; la fibra cruda aumenta de las 24 a las 48 horas del proceso encontrándose valores altos para las inclusiones de $30 \%$ zanahoria y $50 \%$ papa. Se concluye que le proceso fermentativo permite mejorar el valor nutricional de los desechos utilizados siendo una alternativa para utilizarlos eficientemente en la alimentación animal.

Palabras Clave: durazno, fermentación en estado sólido, manzana, papa, zanahoria,

\section{ABSTRACT}

Study to determine compositional quality of a food prepared by solid state fermentation with agricultural and agroindustrial residues such as carrot-apple and peach, stimulated by a microbial preparation based on lactic acid bacteria. Eight treatments T1 (30\% potato) were evaluated; T2 (30\% carrot); T3 (30\% apple); T4 (30\% peach); T5 ( $50 \%$ potato) T6 (50\% carrot); T7 ( $50 \%$ apple); T8 (50\% peach); mixed with additives such as: $0.15 \%$ calcium carbonate, urea, minerals, molasses, and magnesium sulfate. Using laboratory techniques, $\mathrm{pH}, \mathrm{FC}, \mathrm{PC}$, ash, MS and humidity were evaluated at 0,24 and 48 hours of the process. The obtained results evidenced a decrease of the $\mathrm{pH}$ stabilizing between 4.4 and 5.1; the crude protein increases at each sampling point, treatments with different percentages of potato inclusion report higher values; the humidity remained between 35 to $74 \%$, optimum for the fermentation process, the ash between $5 \%$ and $7.8 \%$; dry matter values increased at each evaluation point, the best results were observed with the $50 \%$ inclusion of potato and carrot with values of $62.18 \%$ and $63.67 \%$, respectively; the raw fiber increases from 24 to 48 hours of the process, being high values for the inclusions of $30 \%$ carrot and $50 \%$ potato. It is concluded that the fermentation process allows to improve the nutritional value of the waste used being an alternative to use them efficiently in animal feed.

Keywords: peach, solid state fermentation, apple, potato, carrot 


\section{Introducciòn}

La alimentación es considerada el eje fundamental en los diferentes tipos de producción animal de este depende el buen desarrollo de los parámetros productivos, sin embargo los altos costos de las materias primas para la fabricación de concentrados eleven de forma significativa los costos de producción de ahí la importancia de implementar nuevas alternativas de alimentación utilizando nuevas tecnologías dentro de las cuales se encuentra la fermentación en estado sólido. Los procesos de fermentación en estado sólido (FES), se llevan a cabo sobre un sustrato el cual permite la inoculación y el crecimiento de microorganismos, con el fin de aumentar el valor nutricional de un producto mejorando las posibilidades de conservación, cambiando las características físico-químicas como el color y el sabor de los mismos ( Becerra Bernal A, 2006).

La Fermentación en Estado Sólido (FES) es utilizada para la obtención de materias primas para la nutrición animal, a nivel industrial, farmacéuticas, para la obtención de enzimas, etanol, proteína unicelular, champiñones, ácidos orgánicos y aminoácidos (Cantero, Ory, \& Webb, 2009).

En este sentido, uno de los temas más investigados en los tiempos actuales es la utilización de diferentes desechos de tipo agrícola y agroindustrial que permitan disminuir los altos costos de alimentación en la producción animal de modo tal que estos subproductos puedan ser utilizados de forma parcial o total como materias primas y que además constituyan una fuente importante de nutrientes logrando tener un alimento de buena calidad que permita cubrir los requerimientos de producción y mantenimiento de los animales.(E. de J. Muñoz Prieto, Rivas, \& Sánchez, 2012) A nivel mundial se han empleado desechos de cultivos como la caña de azúcar, el bagacillo de arroz, el garbanzo, los frutales, el cacao, la yuca, entre otros(Cortés Díaz, Prieto Suárez, \& Rozo Nuñez, 2015), que por contener una cantidad importante de carbohidratos, se convierten en sustratos adecuados para el desarrollo de procesos FES.

Por lo anterior, este estudio pretende evaluar el uso de desechos agrícolas con un proceso de fermentación en estado sólido (FES) sobre su calidad composicional como dieta asistida con un preparado microbiano en base a bacterias ácido lácticos. Para ello, se analizaron los parámetros como fermentación y calidad nutricional en el producto final y el proceso. 


\section{Ubicación}

El estudio se llevó a cabo en el Laboratorio de Nutrición Animal de la Universidad Pedagógica y Tecnológica de Colombia (UPTC), ubicada en la avenida central del norte, vía Tunja - Paipa, en el municipio de Tunja, Departamento de Boyacá.

\section{Preparación del alimento}

Los materiales fueron llevados al laboratorio de nutrición animal para su preparación y posterior estabilización. La zanahoria y la papa fueron lavadas para retirar las impurezas y material orgánico. Se cortaron en partículas de aproximadamente 0.5 $\mathrm{cm}$ y se mezclaron con el resto de ingredientes, se obtuvieron muestras de $1 \mathrm{~kg}$ de alimento las cuales se llevaron a incubación a $20^{\circ} \mathrm{C}$.

En esta fase se tomaron diferentes porcentajes de las materias primas utilizadas como lo son papa, zanahoria, manzana, durazno, repila de arroz, torta de palmiste, Cascarilla de café, se obtuvieron 8 tratamientos los cuales fueron mezclados con diferentes aditamentos como: $0.15 \%$ de carbonato de calcio, $1 \%$ de urea, $2 \%$ BAL, $3 \%$ minerales, $10 \%$ melaza, y $0.2 \%$ sulfato de magnesio; los minerales antes mencionados son comerciales de tipo analítico.(Tabla 1)

pH: se midió utilizando un potenciómetro electrónico marca okaton $\Re$. Se tomó 5 mg de cada submuestra a las 0, 24, y 48 horas del proceso de fermentación, se disolvió cada una en $5 \mathrm{ml}$ de agua, se colocó en agitación por 10 minutos, se filtró y se tomó el $\mathrm{pH}$ respectivo

Proteína (PC): El procedimiento que se utilizó para determinar la cantidad de proteína cruda se conoce como el método de Kjeldahl; el material a analizar primero se digirió en $\mathrm{H}_{2} \mathrm{SO}_{4}$, ácido que convierte el $\mathrm{N}$ en $\left(\mathrm{NH}_{4}\right) 2 \mathrm{SO}_{4}$, se enfrío la mezcla y se diluyó con agua, se neutralizo con $\mathrm{NaOH}$ el cual transforma el $\mathrm{N}$ en un amoniaco ionizado (Borato de amonio), por último se destila la muestra y se titula con ácido clorhídrico 0.2 N (Sepúlveda Delgado, Suárez Aguilar, Patarroyo Mesa, Bautista Díaz, \& Canaria Camargo, 2015)(Pandey, C.R., Rodríguez-León, \& Nigam, 2001).

Cenizas: Representan el contenido en minerales del alimento, estas suponen menos del $5 \%$ de la materia seca de los alimentos. Las cenizas se determinan como el residuo que queda al quemar en un horno o mufla los componentes orgánicos a $550^{\circ} \mathrm{C}$ durante 5 horas (Pandey et al., 2001). 
Materia Seca (MS): secado del alimento a $60^{\circ}$ por 48 horas.

Fibra cruda: Este método se basa en la digestión ácida y alcalina de la muestra obteniéndose residuo de fibra cruda y sales que con calcinación posterior se determina la fibra cruda. Se toman $2 \mathrm{~g}$ de la muestra se llevan a ebullición, se le adicionaron $25 \mathrm{ml}$ de hidróxido de sodio $(0.556 \mathrm{~N})$ durante 30 minutos, con recirculación constate de agua, se realizan lavados con agua destilada caliente; seguido de esto se adicionaron $25 \mathrm{ml}$ de ácido sulfúrico $(0.6 \mathrm{~N})$ y se deja en el extractor de fibra cruda durante 30 minutos, pasado este tiempo fueron colocadas en la mufla a $600^{\circ} \mathrm{C}$ por aproximadamente tres horas, la pérdida de peso debido a la incineración corresponde a la FC (Pandey et al., 2001).

\section{Diseño experimental}

Se utilizó un diseño completamente al azar se definieron 8 tratamientos correspondientes a T1 (30\% papa); T2 (30\% zanahoria); T3 (30\% manzana); T4 (30\% durazno); T5 (50\% papa) T6 (50\% zanahoria); T7 (50\% manzana); T8 (50\% durazno) cada uno con tres repeticiones para un total de 24 Unidades experimentales.

Se midieron parámetros como materia seca (MS), fibra cruda (FC), cenizas (CZ), proteína cruda (PC) y humedad a las 0,24 y 48 horas del proceso de fermentación. Análisis estadístico

Para el análisis estadístico se utilizó análisis de varianza (ANOVA), y las diferencias estadísticas se determinaron por comparación de medias por el método Duncan mediante el uso del software SAS v 9.2.

\section{Resultados y Discusiòn.}

pH: Los valores de pH descienden constantemente en cada punto de muestreo. El valor más alto de $\mathrm{pH}$ fue de 6.04 corresponde al T8 (50\% durazno) a las 0 horas del proceso de fermentación, el valor más bajo fue de 4,34 para el tratamiento T7 ( $50 \%$ manzana) a las 48 horas del estudio.

El tratamiento con mayor estabilidad fue el T3 (30\% manzana) con porcentajes de $5.8 ; 5.3$ y 4.6 a las 0,24 y 48 horas respectivamente (E. Muñoz Prieto, Palacios 
18

Alquisira, \& Rius Alonso, 2012). Así mismo el T8 (50\% durazno) reportó valores de 6,$0 ; 5,7 ; 4,7$ durante el tiempo de estudio.

Varios autores llegan a la conclusión que el pH es un parámetro el cual se debe mantener dentro del rango de 3.5 y 6 esto con el fin de permitir un adecuado crecimiento de los microorganismos en el proceso de fermentación en estado sólido (Pandey et al., 2001). El pH cambia por diferentes razones normalmente disminuye por la secreción de ácidos orgánicos como el acético y láctico durante el proceso, así mismo la fuente de nitrógeno influye de forma directa sobre los porcentajes de pH (Toledo, 2008).

PROTEÍNA CRUDA (PC): Los niveles de proteína aumentaron de forma constante en cada punto de muestreo. Se presentaron diferencias significativas $(<0.01)$ para las 24 y 48 horas del proceso de fermentación. Los valores más altos se reportaron a las 48 horas del proceso para los tratamientos T3; T4 y T5 con porcentajes de $18.8 ; 20.9$ y 22.5 respectivamente. El mejor tratamiento fue el T5 (50\% papa) el cual al inicio del proceso reportó valores de $13 \%$ de PC el cual aumentó a $22.54 \%$ al final del estudio.

Empleando diferentes sustratos como maíz molido, sorgo molido, pulpa de cítrico deshidratada y pulidora de arroz y fuentes energéticas se logró estimar que los valores de PC ascienden a $17.52-22.98 \%$ al someterlos a un proceso de FES, afirmando que este tipo de alimentos puede competir con alimentos comerciales; además, se demostró el potencial que tienen los procesos de FES en la producción de alimentos de alto valor nutricional para los animales, a partir de materiales de bajo contenido de proteína y que están disponibles en la región (Ramos Juárez, 2005). El incremento de la proteína utilizando otros sustratos también fue comprobado por Valdivie et al. (1997), citado por Cárdenas et al. (JR et al., 2008), quien informó que en caña de azúcar fermentada con diferentes ingredientes mediante FES, los valores de PC pasaron de 11.5 a $16.3 \%$ proporciones de incremento semejantes a las halladas para la papa en el presente estudio.

Así mismo, en ensayos en donde se empleaba bagacillo de retorno en procesos de 24 horas de fermentación y con inclusiones del $20 \%$ de pulido de arroz, lo valores alcanzados fueron de 21.1 a $27.1 \%$ (Elías, 2000). En otro estudio en el Valle del Cauca (Colombia), utilizando yuca sometida a fermentación en estado sólido se logró aumentar el porcentaje de PC de 3 a 9.2\% (Espinosa Arias, 2008).

CENIZAS (CZ): Las cenizas de un alimento son definidas como el residuo inorgánico que queda al someter la materia orgánica a un proceso de calcinación 
(UNAM, 2008). No se observan diferencias estadísticas entre los tratamientos (> $0.05)$.Los porcentajes más altos de cenizas (CZ) se reportaron para los tratamientos T1 (30\% papa) con valores de 7,8; 8,1 y 8 a las 0,24 y 48 horas respectivamente; así mismo al utilizar una inclusión del $30 \%$ y $50 \%$ de manzana encontramos valores por encima de 7,4 a las 0 horas y llegando a 8,4 a las 48 horas del estudio.

En procesos fermentativos en donde se utilizó desechos de guayaba para la alimentación de ganado en México se pasó de $0,7 \%$ a 1,5\% de CZ sin la adición de materiales secantes ni pre mezclas de minerales (F., 2010). La elevación de los valores de cenizas también fue reportado por reportado por Pérez (1996) (Pérez Quilantan, 1996), quien observó que al someter el mijo de perla (Pennisetum americanum ( $L$ ) Leeke) a fermentación en estado sólido el contenido de cenizas paso de $1.6 \%$ a $2.1 \%$ a las 72 horas de fermentación como consecuencia del metabolismo celular.

El porcentaje de cenizas está relacionado con el contenido de las mismas en las diferentes fuentes energéticas utilizadas en el experimento, el descenso de las cenizas se justificaría debido a que los microorganismos para desarrollar procesos fermentativos requieren de gran cantidad de nutrientes entre ellos los minerales.

HUMEDAD (H): se mantuvo entre $35.4 \%$ y $72.17 \%$ entre las 0 y 48 horas del proceso de fermentación. Estos valores según Peláez(2011), son óptimos ya que es de vital importancia reducir la humedad $<80 \%$ para optimizar las condiciones de FES y del crecimiento microbiano.

Como se observa en la figura 4, los valores más altos de humedad los reporta el tratamiento T2 a las 0 y 48 horas de muestreo con valores de $72,1 \%$ y $72,14 \%$ respectivamente. Así mismo el T7, con valores de $74.3 \%$ y $72.31 \%$ a las 0 y 24 horas de muestreo. Los porcentajes más bajos de humedad se encontraron en los tratamientos T6 Y T5 con valores de $36.33 \%$ y $37.82 \%$ respectivamente a las 48 horas de muestreo. En el T3 se observa un descenso de los porcentajes de humedad en cada uno de los puntos de muestreo presentando valores de $67.5 \%, 65.19 \%$ y $63.93 \%$.

Según Pastrana (1996) (Pastrana, 1996) citado por Moyano(2014) (Moyano, 2014), un contenido alto de humedad provoca numerosas situaciones, descensos de la porosidad y por consiguiente la difusión del oxígeno, aumenta el riesgo de contaminación bacteriana e incrementa la formación del micelio aéreo efectos que se deben prevenir en una fermentación en estado sólido, un fenómeno igualmente indeseable se observa en cultivos con una reducida actividad del agua debido a que 
cuando desciende por debajo del límite de crecimiento, se puede producir esporulaciones de microorganismos. Por lo general el contenido inicial de la humedad del sustrato está entre el 30 y el 75\%, durante el proceso de fermentación se presentan reducciones debido a la perdida por evaporación como resultado de la actividad metabólica de los microorganismos (Sousa \& Pinto, 2010) (Stabilization et al., 2015) (Medina, García, \& Sánchez, 2015). El nivel de humedad en los procesos fermentativos cumple funciones importantes como disolver homogéneamente los nutrientes del medio y facilitar su acceso a la célula, así mismo se encarga de mantener aptas las condiciones del cultivo como temperatura y $\mathrm{pH}$.

MATERIA SECA (MS): Los valores para materia seca (MS) aumentan en cada punto de muestreo, se encontraron en rangos entre $25.7 \%$ a $42.8 \%$ a las o horas; $27.69 \%$ y $64.5 \%$ a las 24 horas y $27.8 \%$ y $63.67 \%$ a las 48 horas del proceso de fermentación.

Los porcentajes de materia presentan un aumento de las 0 a las 24 horas del proceso de fermentación. Los valores más altos se reportan para el T6 (50\% zanahoria) y del T4 (30\% durazno) con valores de $64.5 \%$ y $52,3 \%$ respectivamente.

La disminución de materia seca durante el proceso de FES puede deberse a la fermentación de cierta cantidad de azucares (sacarosa, glucosa, fructosa), al almidón de los sustratos utilizados, a la hidrolisis de la urea y en menor escala a la desaminación de aminoácidos (Ramos Juárez, 2006).

Así mismo para Castillo (2011) (Castillo, Ruiz, Angulo, Rodríguez, \& Elías, n.d.), la disminución de los niveles de materia seca se da por la fermentación de los carbohidratos durante el proceso fermentativo, en donde se va a generar un incremento en los AGV relacionado con los niveles de $\mathrm{pH}$.

Por lo anterior la disminución del porcentaje de materia seca en este estudio está relacionada con la adición de urea y minerales en los diferentes niveles de inclusión en los tratamientos.

FIBRA CRUDA (FC): Los valores se mantuvieron en rangos similares durante los tres puntos de muestreo, se evidenció un aumento en los porcentajes entre las 24 y 48 horas del proceso en los tratamientos en donde se utilizó $30 \%$ de inclusión de materiales como papa, manzana y durazno; así mismo al utilizar $50 \%$ de papa y zanahoria se pudo evidenciar un aumento de los porcentajes a las 48 horas con valores de 7.2 y $6.7 \%$ respectivamente. 
Los valores más bajos se presentaron a las 0 horas para los tratamientos T7 (50\% manzana) con $3.1 \%$ y T6 (50\% zanahoria) con 3.3\% a las 24 horas del proceso fermentativo. El incremento de la fibra puede ser explicado porque el tiempo de fermentación aumenta significativamente el contenido de paredes celulares, en relación al contenido de almidón del producto usado (Aranda, Georgana, Ramos, \& Salgado, 2012). Esto debido al uso de los azúcares que se encuentran en el contenido celular por los microorganismos que se desarrollan en el sistema (Fernández Cabrera, 2009; Ramos Juárez, 2005), proceso que se ve reflejado aproximadamente a las $48 \mathrm{~h}$ de fermentación según (Rodríguez, Boucourt, Elías, \& Madera, 2001; Rodríguez, Elías, Boucourt, \& Núñez, 2001).

\section{CONCLUSIONES.}

Colombia tiene gran diversidad de climas con amplios territorios utilizados para cultivos de frutas, hortalizas, cereales, gramíneas y leguminosas que generan gran cantidad de residuos de cosecha los cuales mediante procesos biotecnológicos como la fermentación en estado sólido se pueden transformar en productos con alto valor nutricional.

El valor nutricional de un alimento fabricado mediante fermentación en estado sólido permite aumentar el porcentaje de proteína el cual se obtiene gracias al trabajo realizado por bacterias generalmente del tipo acido lácticas.

Los subproductos orgánicos son una alternativa para disminuir costos y aumentar en contenido composicional de las materias utilizadas obteniendo alimentos que pueden ser utilizados en la alimentación animal.

\section{Referencias Bibliogrâficas}

Aranda, E., Georgana, L., Ramos, J., \& Salgado, S. (2012). Elaboración de un alimento basado en caña de azúcar a partir de la fermentación en estado sólido y con diferentes niveles de zeolitas. Rev. Cubana Cienc. Agric, 159-163.

Becerra Bernal A. (2006). Aprovechamiento de subproductos de manzana mediante la producción de proteína microbiana con fermentación en estado sólido para la alimentación animal. Universidad Autónoma de Chihuahua. 
Cantero, A., Ory, I., \& Webb, D. (2009). Producción de enzimas hidrolíticas por Arpergillus Awamori sobre jugo de Uva. Universidad de Cadiz.

Castillo, Y., Ruiz, O., Angulo, C., Rodríguez, C., \& Elías, A. (n.d.). Inclusión de residuos de panadería en algunos metabolitos e indicadores bromatológicos de la fermentación en estado sólido del bagazo de manzana. Rev. CubanaCienc. Agríc, 141-144.

Cortés Díaz, G. M., Prieto Suárez, G. A., \& Rozo Nuñez, W. E. (2015). Caracterización bromatológica y fisicoquímica de la uchuva ( Physalis peruviana $\mathrm{L}$. ) y su posible aplicación como alimento nutracéutico. Ciencia En Desarrollo, 6(1), 87-97.

Elías, A. \& L. O. (2000). Inclusión de niveles de harina de soya desgrasada y sin desgrasar en la fermentación de la caña de azúcar en estado sólido. Rev. Cubana Cien. Agric., 143.

Espinosa Arias, J. (2008). Evaluación de dos procesos para mejorar la calidad nutricional de la harina de yuca (raíces y follaje) como alimento para cerdos en la etapa de ceba. Universidad de San Buenaventura.

F., A. (2010). Efecto de los niveles vitafert y melaza en la pollinaza fermentada aeróbica. Instituto de enseñanza e investigación en ciencias agrícolas.

Fernández Cabrera, C. (2009). Efectos de los niveles de urea en el Sacchapulido sobre los patrones de fermentación ruminal. Tabasco: Colegio de Postgraduados, Institución de enseñanza e investigación en ciencias agrícolas.

JR, C., EM, A., D, H., LC, L., JA, R., \& S, S. (2008). Obtención de un alimento fermentado en estado sólido a partir del bagacillo de retorno, pulido de arroz e inóculos. Su utilización en la alimentación animal. Rev. Cubana Cien. Agric, 173-176.

Medina, W., García, D., \& Sánchez, F. (2015). Aves y mamíferos de bosque altoandinopáramo en el páramo de Rabanal ( Boyacá-Colombia ). Ciencia En Desarrollo, 6(2), 185198.

Moyano, M. (2014). Fermentación en estado sólido (FES) de la papa (Solanum tuberosum), como alternativa tecnológica para la alimentación animal. Universidad Nacional de Colombia.

Muñoz Prieto, E. de J., Rivas, B., \& Sánchez, J. (2012). NATURAL POLYMER GRAFTED WITH SYNTETHIC MONOMER BY MICROWAVE FOR WATER TREATMENT - A REVIEW. Ciencia En Desarrollo.

Muñoz Prieto, E., Palacios Alquisira, J., \& Rius Alonso, C. (2012). MICROWAVE AND ULTRASOUND ACTIVATION EFFECT ON CATIONIZATION OF CORN AND POTATO STARCHES. Ciencia En Desarrollo.

Pandey, A., C.R., S., Rodríguez-León, J. A., \& Nigam, P. (2001). Solid-state fermentation in biotechnology. Fundamentals and Applications. Asiatech Publishers, 221.

Pastrana, L. (1996). Fundamentos de la fermentación en estado sólido y aplicación a la 
industria alimentaria. Ciencia Y Tecnología Alimentaria, 4-12.

Pérez Quilantan, L. (1996). Fermentación en estado sólido del Mijo de perla (Pennisetum americanum (L.) Leeke) por Rhizopus oligosporus para la obtención de un producto rico en proteína. Universidad Autónoma de Nueva León.

Ramos Juárez, J. (2005). btención de un concentrado energético proteínico por fermentación en estado sólido de la caña de azúcar para bovinos en ceba. La Habana: Instituto de Ciencia Animal, Departamento de ciencias biofisiológicas.

Ramos Juárez, J. (2006). Obtención de un concentrado energético proteínico por fermentación en estado sólido de la caña de azúcar para bovinos en ceba. La Habana: Instituto de Ciencia Animal, Departamento de ciencias biofisiológicas.

Rodríguez, Z., Boucourt, R., Elías, A., \& Madera, M. (2001). Dinámica de fermentación de mezclas de caña (Saccharum officinarum) y boniato (Ipomea batata). Rev. Cubana Cienc. Agric, 147-151.

Rodríguez, Z., Elías, A., Boucourt, R., \& Núñez, O. (2001). Efectos de los niveles de nitrógeno ureico en la síntesis proteica durante la fermentación de mezclas de caña (Saccharum officinarum) y boniato (Ipomea batata Lam.). Rev. Cubana Cien. Agric, 29-36.

Sepúlveda Delgado, O., Suárez Aguilar, Z. E., Patarroyo Mesa, M., Bautista Díaz, S., \& Canaria Camargo, L. C. (2015). Estudio del comportamiento e impacto de la climatología sobre el cultivo de la papa y del pasto en la región central de Boyacá empleando los sistemas dinámicos in the Central Region of Boyacá Using Dynamic Systems. Ciencia En Desarrollo, $6(2), 215-224$.

Sousa, B., \& Pinto, R. (2010). Biotechnological reuse of fruit residues as a rational sitategy for Agroindustrial resources. Journal of Technology Managment \& Innovation, 104-113.

Stabilization, O., Plukenetia, I., Linneo, V., Vaccinium, M., Sw, M., \& Addition, S. (2015). Estabilización oxidativa del aceite de Sacha inchi ( Plukenetia volubilis Linneo ) con suspensiones de mortiño ( Vaccinium meridionale SW ). Ciencia En Desarrollo, 6(2), 141153.

Toledo, M. (2008). Residuos de maíz y quínua como potenciales para el cultivo de hongos comestibles Pleurotus ostreatus. Escuela Superior Politecnica Chimborazo. 
Tabla 1. Tratamientos

\begin{tabular}{|c|c|}
\hline Tratamiento & Ingredientes \\
\hline $\mathrm{T1}$ & $\begin{array}{l}\text { 30\% Papa - 15\% Palmiste - 20\% Cascarilla de café - 20\% Pulidura } \\
\text { de Arroz- } 8 \% \text { Melaza- } 5 \% \text { Inoculo Bacteriano- 0,25 \% Carbonato de } \\
\text { calcio- } 0.75 \% \text { Minerales }\end{array}$ \\
\hline $\mathrm{T} 2$ & $\begin{array}{l}\text { 30\% Zanahoria - 15\% Palmiste - 20\% Cascarilla de café - 20\% } \\
\text { Pulidura de Arroz- } 8 \% \text { Melaza- 5\% Inoculo Bacteriano- 0,25\% } \\
\text { Carbonato de calcio- } 0.75 \% \text { Minerales }\end{array}$ \\
\hline T3 & $\begin{array}{l}\text { 30\% Manzana - 15\% Palmiste - 20\% Cascarilla de café - 20\% } \\
\text { Pulidura de Arroz- } 8 \% \text { Melaza- } 5 \% \text { Inoculo Bacteriano- 0,25\% } \\
\text { Carbonato de calcio- } 0.75 \% \text { Minerales }\end{array}$ \\
\hline T4 & $\begin{array}{l}\text { 30\% Durazno - 15\% Palmiste - 20\% Cascarilla de café - 20\% } \\
\text { Pulidura de Arroz- } 8 \% \text { Melaza- 5\% Inoculo Bacteriano- 0,25\% } \\
\text { Carbonato de calcio- } 0.75 \% \text { Minerales }\end{array}$ \\
\hline T5 & $\begin{array}{l}\text { 50\% Papa - 15\% Palmiste - 20\% Cascarilla de café - 8\% Melaza- 5\% } \\
\text { Inoculo Bacteriano- 0,25 \% Carbonato de calcio- } 0.75 \% \text { Minerales. }\end{array}$ \\
\hline T6 & $\begin{array}{c}50 \% \text { Zanahoria - 15\% Palmiste - 20\% Cascarilla de café - } 8 \% \\
\text { Melaza- } 5 \% \text { Inoculo Bacteriano- } 0,25 \% \text { Carbonato de calcio- } 0.75 \% \\
\text { Minerales. }\end{array}$ \\
\hline T7 & $\begin{array}{c}50 \% \text { Manzana - } 15 \% \text { Palmiste - } 20 \% \text { Cascarilla de café - } 8 \% \text { Melaza- } \\
\text { 5\% Inoculo Bacteriano- } 0,25 \% \text { Carbonato de calcio- } 0.75 \% \\
\text { Minerales. }\end{array}$ \\
\hline
\end{tabular}




\begin{tabular}{|c|c|}
\hline T8 & $\begin{array}{c}50 \% \text { Durazno - 15\% Palmiste - } 20 \% \text { Cascarilla de café - } 8 \% \text { Melaza- } \\
5 \% \text { Inoculo Bacteriano- } 0,25 \% \text { Carbonato de calcio- } 0.75 \% \\
\text { Minerales. }\end{array}$ \\
\hline
\end{tabular}

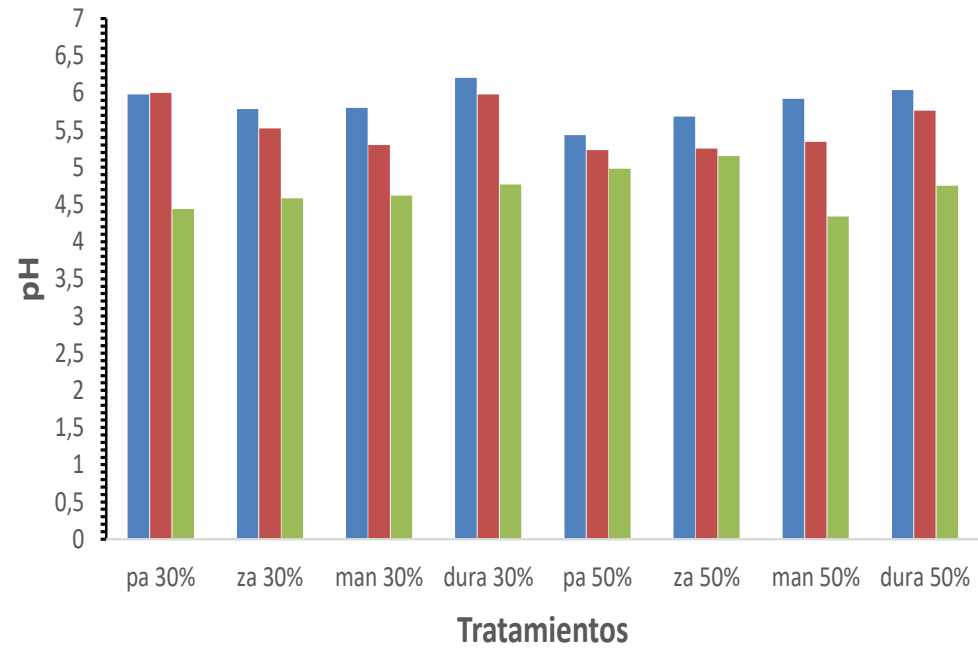

Figura 1. Indicador: $p H$

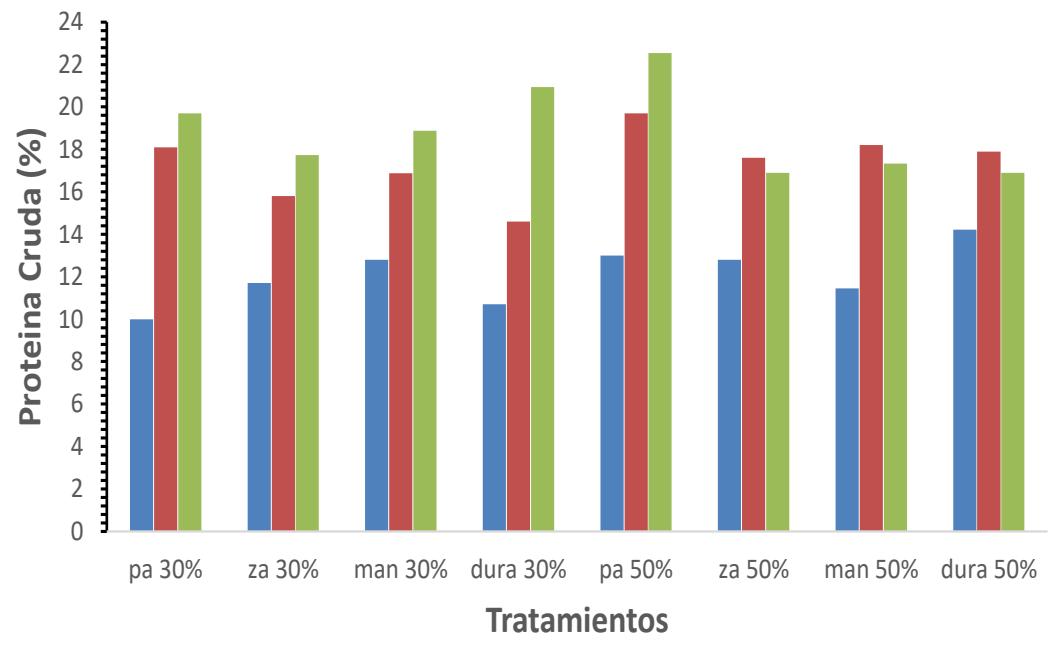

Figura 2. Indicador = Proteína Cruda $(P C)$ 


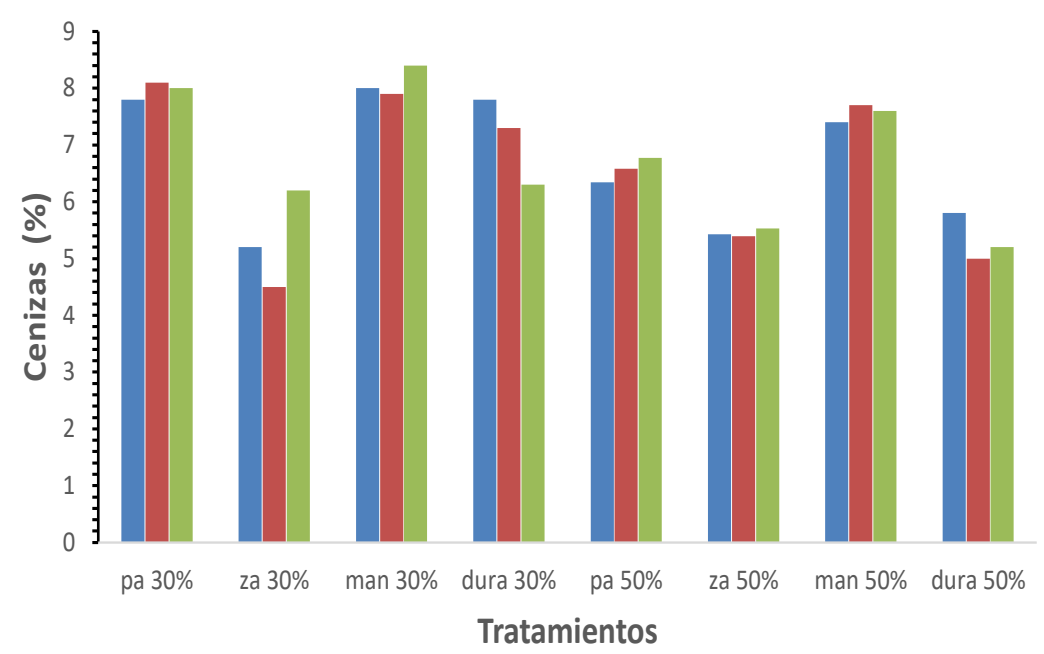

Figura 3. Indicador: Cenizas (CZ).

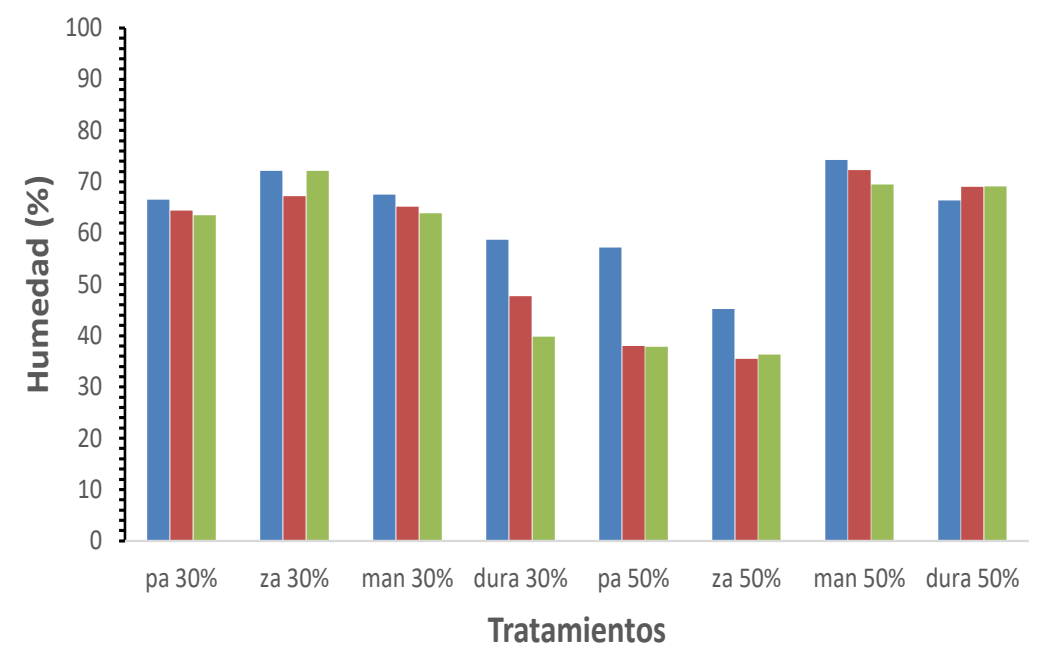

Figura 4. Indicador: Humedad (H) 


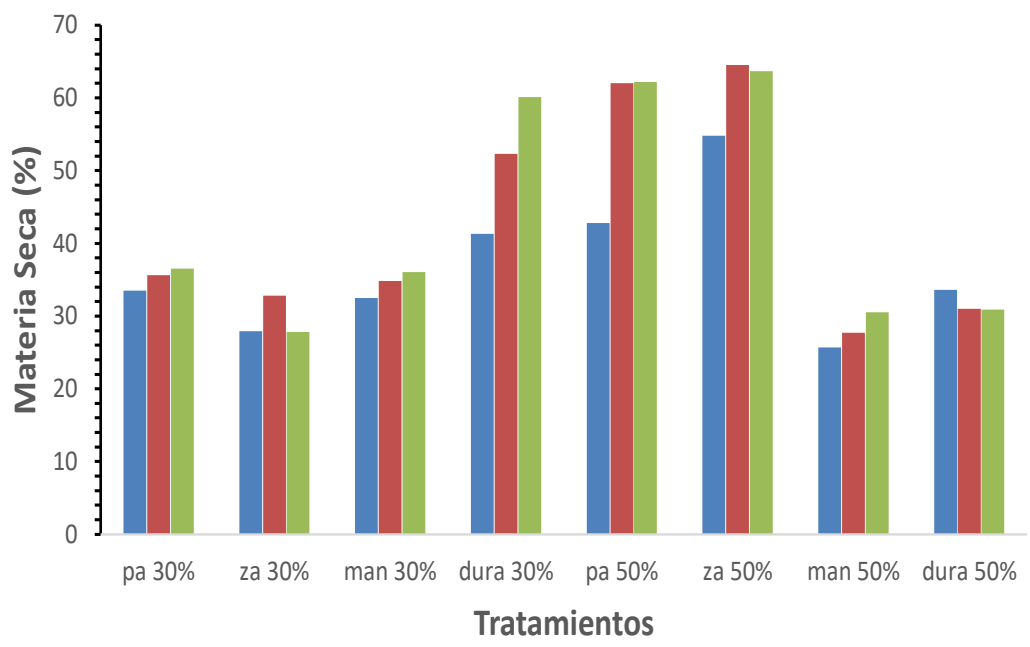

Figura 5. Indicador: Materia Seca (MS).

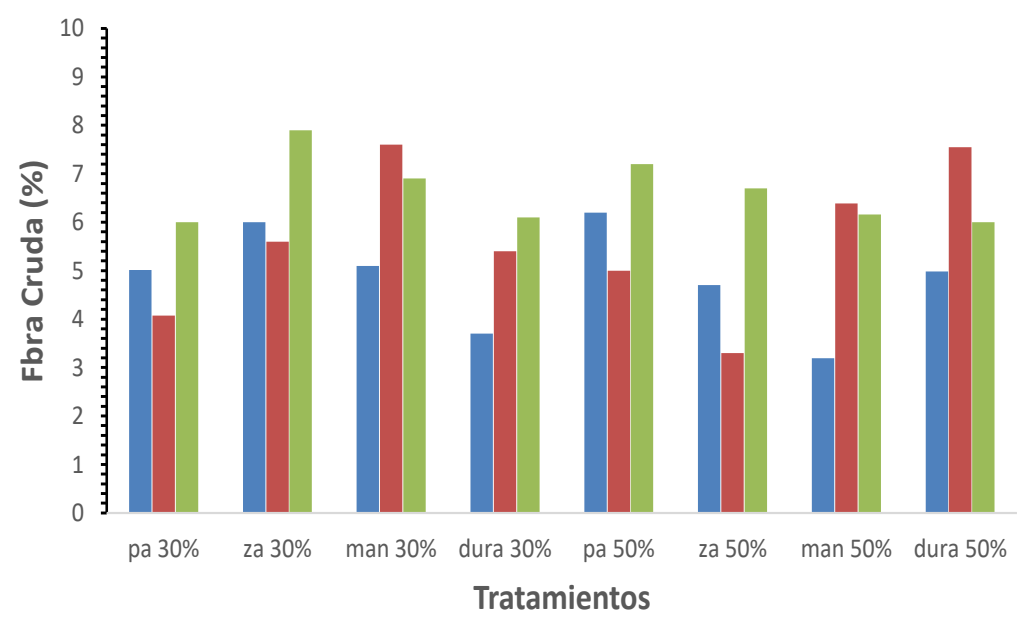

Figura 6. Indicador: Fibra Cruda (FC)

*Para citar este artículo: Saavedra Montañez G.F .; Cala Guerrero D.C .; Rodríguez Molano C.E.Evaluation of agricultural subproducts submitted to fermentation in a solid state. Revista Bistua.2018.16(1):13-27

+ Autor para el envió de correspondencia y la solicitud de las separatas: Rodríguez Molano C.E. Grupo de Investigación en Bioquímica y Nutrición Animal, Dirección de Investigaciones, Facultad de Ciencias Agropecuarias, Universidad Pedagógica y Tecnológica de Colombia (UPTC). Tunja. ceromol@gmail.com

Recibido: Noviembre 15 de 2016

Aceptado:Diciembre 12 de 2017 